\title{
Determining patient preferences in the management of neovascular age-related macular degeneration: a conjoint analysis
}

\begin{abstract}
Purpose To determine the opinions from a patient perspective on relevant variables in the delivery of treatment for neovascular age-related macular degeneration (nAMD).

Methods Pilot interviews with patients and doctors were conducted to identify what variables in the provision of a nAMD service were important. This led to the generation of two sets of scenario options. Subsequently 100 patients undergoing active treatment for nAMD in the National Health Service University Hospital, United Kingdom underwent interview assessment. They were asked to rank their preferences for provision of their care with reference to these two sets of scenario options. Using conjoint analysis, percentage preferences, and utility scores for each variable in each scenario design were calculated.

Results Ninety-five patients completed the preference ranking for both scenarios. Eight patients ranked worse vision as preferable to better vision and were excluded on the basis that they had not understood the task. The results of the remaining 87 patients are presented. The most important factor to patients was having good vision, followed by a one-stop service and less frequent follow up. The least important factors were label status of the drug, cost to the health service, and grade of the injector.

Conclusion Patients regard good vision and minimal visits to the hospital above the status of injector, label status of drug, or cost to the NHS.
\end{abstract}

Eye (2016) 30, 698-704; doi:10.1038/eye.2016.18; published online 26 February 2016
JM Baxter, AJ Fotheringham and AJE Foss

\section{Introduction}

Age-related macular degeneration (AMD) is the commonest cause of blindness among elderly people in the developed world. In the United Kingdom, the prevalence of neovascular AMD (nAMD) was estimated to be $245000^{1}$ in 2003 and it is estimated that it will increase to 700000 by $2020 .^{2}$

The introduction of the ranibizumab $b^{3,4}$ has been a major advance for the management of this condition but has also bought its own problems as the assessment and administration of anti-VEGF agents is a major workload for many ophthalmology units and is a major item of expenditure for the healthcare budget. A cheaper option, bevacizumab has been shown to be as effective as ranibizumab ${ }^{5-7}$ but has proven controversial as it is not licensed for intraocular use. This has not prevented bevacizumab been used widely for this condition.

More recently aflibercept has been introduced and this seems to be effective when used on a two monthly rather than a one monthly regimen. ${ }^{8}$

In addition to the issue of cost, there is the issue of workload with an increasing number of units turning to the use of nursing staff to perform the intraocular injections ${ }^{9}$ and issues as to whether it is appropriate to inject patients on the same day as their assessment clinic.

Patient-centred care is ever more important and was a key theme in the report by Robert Francis QC, making sure that patients' voices are heard and used to deliver better services. ${ }^{10}$ One way of ascertaining a patients' preference for a product or service is by assessing 'trade off' using conjoint analysis (CA). Briefly, CA is a 
technique that has recently been used in healthcare research particularly to determine patients preferences for service development ${ }^{11,12}$ and in ophthalmology to determine patients preferences for treatment of various ophthalmic conditions. ${ }^{13-15}$ The full concept method of analysis generates a number of profiles or scenarios with the attributes of interest for the service package or product represented. The subject has to evaluate the scenarios and had to make trade-offs to rank the scenarios. Two additional scenarios, termed holdouts, were also generated in order to assess the validity. These holdouts are generated from another random plan and not the experimental orthogonal plan. The analysis allowed us to discover the relative importance of each factor for individuals but also more importantly help to identify trends in a group. CA generates a 'utility score', which is a numeric value of how desirable or undesirable a patient values the aspects presented in the scenario. A mean 'utility score' will then show which factors the whole group finds desirable.

The aim of this study was to elucidate the factors that are important to the patients attending our department with nAMD that affects how their treatment is delivered. This information provides insights into aspects of our management that are considered important by patients and to help guide local service improvements. We were interested also in views on whether a one-stop or twostop service (assessment and treatment occurring at either the same visit or different visit) and whether they would accept off-label medication or a nurse, rather than a doctor lead injection service.

\section{Materials and methods}

Under local guidance, obtaining patient views did not require formal ethical approval but was approved by the head of service. The study was done on patients attending clinics dedicated to the management of AMD in a publically funded (NHS) University Hospital setting (the Queen's Medical Centre, Nottingham, UK). The hospital itself is based in an urban setting (Nottingham, UK) but covers both an urban and rural population. Accordingly, patients with short travel times were mainly from an urban setting and long travel times from a rural setting.

The service in Nottingham is arranged such that patients belong to 'the service' rather than a particular doctor and accordingly their care was delivered by a team of doctors rather than an individual. As a result, the treatment regimen followed was varied and the treatment was a combination of ranibizumab and bevacizumab (the study was conducted prior to the widespread use of aflibercept). In brief, all patients received a course of three monthly injections of either ranibizumab or bevacizumab and then seen either monthly or bi-monthly (for some patients treated with bevacizumab) and retreatment performed on an as required basis. Patients had to have a presenting visual acuity between $6 / 12$ and $6 / 96$ to be eligible for treatment in accordance with NICE guidelines.

Patients with nAMD were asked whether they agreed to have their views elicited prior to interview. Pilot interviews were conducted on seven patients to identify their main concerns with respect to how macular clinics are run. The patients were invited to express their concerns (largely burden of frequent attendances, having to return for an injection, long waiting time, and desire for good vision). This list of factors is very similar to that found by others using a focus group. ${ }^{16}$ In addition, the head of service views were elicited and these included the use of off-label medication and the acceptability of nurse injectors.

Seven factors of importance were elicited and this number is too many to put into a single conjoint study design. These factors were divided into two groups with one (monthly vs bi-monthly review) appearing in both designs. The factors for the first design were:

1. Length of wait (average $1 \mathrm{~h}$, average $2 \mathrm{~h}$ ).

2. Frequency of visits ( 4 weekly, 8 weekly).

3. Clinic setup: (1 stop, 2 stop).

4. Training of healthcare professional administering injection (nurse practitioner, doctor).

The factors for the second design were:-

1. Vision (good, moderate, poor).

2. Cost to the NHS (high, low).

3. Frequency of visits ( 4 weekly, 8 weekly).

4. Drug injected status (on label, off label).

The number of possible combinations of the above scenarios is 16 for Task 1 and 24 for Task 2. As it is not feasible to ask patients to consider all these combinations, we used a factor design (called 'orthoplan' in SPSS) to randomly generate an 'orthogonal array' of eight scenarios and each of these scenarios was transcribed onto a separate card, and so that the patient could order the scenarios by ordering these cards in order of preference. It is assumed that interactions between the variables are negligible. Two holdout scenarios were also generated from another random plan (not the experimental orthogonal plan), which would not be used in the final analysis, but used to assess internal validity (the programme compared the ranked position of the two holdout cards with the predicted position taken from the CA). The correlation between the predicted and observed 
rank for the holdout card was calculated using the nonparametric Kendall's tau test.

Each task thus consisted of 10 scenario cards, which the patient would be asked to rank in order of their preference. The order in which the variables were presented on the scenario cards was determined by a random number generator. The cards were in large print, laminated accompanied by a definition sheet for each task.

The definitions provided to the patients are shown in Table 1. An example card is shown in Figure 1. The inclusion criteria were diagnosis of nAMD, vision 6/12-6/96 at presentation, age $>50$ years, at least 3 previous injections, and agreeing to take part.

Patients, who met the inclusion criteria, were approached in an opportunistic manner during routine macular clinic attendances were invited to participate in the study. They were taken into a separate room where they were shown a study information sheet and verbal consent gained. If the patient wished to continue they were shown each task's information and definition sheet and asked to rank the scenarios (1-10) in order of their preference. All the interviews were conducted by two interviewers (JMB and AF).

The patients' preferences were recorded on a standardised data collection sheet, which also contained a hospital identifier (only to exclude duplicates), age, gender, current vision in each eye recorded as LogMAR, count fingers, hand movements, and no perception of light eye (the later three recorded as $+2,+3$, and +4 , respectively), travel time to the hospital $(\mathrm{min})$ and number of previous injections (in groups 3-5, 6-10, 11-15, and 16+). The data were stored in a database (Microsoft Excel) and CA was performed using the 'conjoint' procedure in SPSS categories (SPSS version 6, SPSS Inc., Chicago, IL, USA). The conjoint procedure takes the ranking of different scenarios for each patient and through a series of linear regressions, generates utility scores for each option. Each variable was specified as linear. SPSS calculates a regression coefficient for each variable, and the utility score is the product of the coefficients times the option. The relative importance of each variable can also be expressed in percentage terms (by taking the range of utility scores for any variable

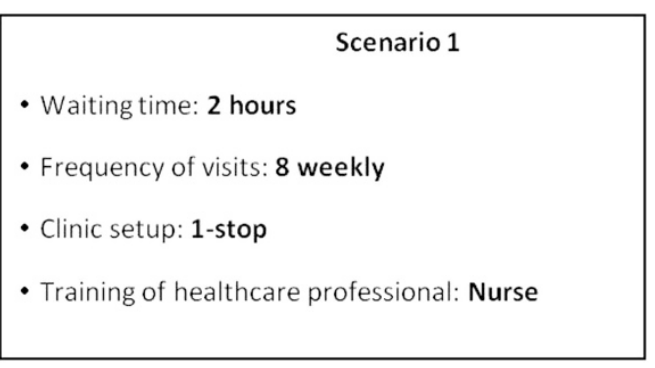

Figure 1 Example of a scenario card shown to patients.

Table 1 Definitions provided to patients

- Length of wait-this is the average waiting time from arrival to finishing in the clinic per visit

- Frequency of visits-this is how often you have to come to clinic to be assessed (may require injection or not)

- Clinic setup-If an injection is required

- 1 stop-having injection on the same day

- 2 stop-required to return on a separate day for the injection

- Training of healthcare professional

- Nurse practitioner-a nurse who has undergone additional training to perform injections

- Doctor-a doctor who has undergone additional training to perform injections

- Vision

- Good-able to read small print/prices in supermarkets with good lighting

- Moderate-able to recognise faces and read newspaper headlines/writing on TV (not small print)

- Poor-able to navigate around a room and make out large objects, not able to see faces/TV/read

- Cost to the NHS - treatment is always free at the point of delivery, but different treatments have different costs to the health service itself

- Low cost- $£ 50$

- High cost—£500

- Drug injection label—a drug can be used to treat different conditions (for example, aspirin is used for pain relief (headache) and used to thin the blood (to prevent heart attacks and strokes). Each type of use is called a label and licensed drugs can have many labels. A drug may be 'off label' if the manufacturer has not applied for recognition (label) to use this drug for a particular condition. For example, aspirin is used widely off label for prevention of heart attacks and strokes. If a drug is known to be safe and to treat a particular condition, then it can be used off label with the patients consent. Drugs may be

○ On label

○ Off label 
(highest minus lowest) and dividing it by the sum of all the utility ranges and multiplying by 100).

Then a multivariate linear regression $(P$ for entry $<0.05$ and for removal $>0.1$ ) was undertaken. Variables entered in the regression model as independent variables were age, gender, number of injections, travel time, use of hospital transport, and the vision in the better of the two eyes. The utility scores for each of the patient ranked factors in the two tasks were the dependent variables. Eight models were generated, one for each of the seven factors (one factor appearing twice; frequency of visit appearing in both models).

Patient preferences exhibiting the phenomenon of reversal for the vision variable were excluded from the analysis. A reversal is deemed to have occurred when the patient chooses an option normally considered unfavorable such as having poor vision. This was felt to be an indicator of lack of understanding of the instructions given to perform the ranking procedure. The importance score was derived from the utility scores from each factor using the methodology we have previously published. ${ }^{13-15}$

\section{Results}

Initial analysis showed in the second task that vision was the single most important factor and by a large margin accounting for over $60 \%$; yet, eight patients had a small preference for poor vision. It was clear that some patients found the task of ordering scenarios cognitively demanding and the most likely explanation was that these eight patients could not comply with the task and instead ordered the scenarios randomly. Excluding these eight patients made no difference to the conclusions of the study, but it seemed clear that their responses were uninformative and so excluded. Five other patients failed to complete the tasks and this left 87 for whom the analysis was performed.

The population demographics are shown in Table 2. All patients had a minimum of 3 injections and $74 \%$ had $>5$ injections, $37 \%$ had $>10$ and $30 \%>15$ injections.

The results of the CA are shown in Tables 3 and 4 .

The two holdout cards in each task showed a Kendall's tau coefficient of 1 indicating extremely high validity of each task. In task 1, 22 patients had one reversal and 3 patients had two reversals. In task 2, 26 patients had 1 reversal and 4 patients had 2 reversals.

Table 2 Patient demographics

\begin{tabular}{ll}
\hline Mean age (range) & 81 (67-94) years \\
Gender & $34 \%$ male/66\% female \\
Mean travel time to hospital (range) & $48(5-120) \mathrm{min}$ \\
Use of hospital transport & $7 \%$ \\
\hline
\end{tabular}

Eight linear regression models were generated, one model for each factor, and the independent variables were visual acuity in better eye, visual acuity in worse eye, age, gender, travel time, and number of injections, using stepwise linear regression and the results are summarised in Table 5.

The multivariate linear regression model for the factor of cost to the NHS showed that patient age and whether they used hospital transport were predictors of importance being attached to low cost to the NHS. The only predictor in the model for whether there was a preference to the medication being on or off label, was travel time with those living near the hospital having a preference for the drug to be on label.

For waiting time in clinic, there was an inverse relationship with the visual acuity in the better eye. Those with poor vision were prepared to wait longer in the clinic.

Travel time did predict the utility of having treatment at the same visit as the assessment, but no other variables entered the model.

None of the variables predicted the utility of being injected by a doctor or nurse. For whether they came monthly or bi-monthly, one design had no predictor variables and the other model showed a weak preference for women to come less frequently.

Table 3 Utility scores, mean importance, and relative importance for each variable in Task 1

\begin{tabular}{llrrc}
\hline Variable & Option & $\begin{array}{c}\text { Mean } \\
\text { Utility } \\
\text { score }\end{array}$ & SEM & $\begin{array}{c}\text { Mean } \\
\text { importance } \\
(\%)\end{array}$ \\
\hline Healthcare professional giving injection & $\begin{array}{l}\text { Doctor } \\
\text { Nurse }\end{array}$ & $\begin{array}{r}0.3912 \\
-0.3912\end{array}$ & 0.083 & 15 \\
Clinic setup & 1 Stop & 1.4029 & 0.084 & 41 \\
Frequency of visits & 2 Stop & -1.4029 & & \\
& Monthly & 0.5765 & 0.21 & 24 \\
Waiting time & 2 Monthly & 1.1529 & & \\
& 1 h & -1.2765 & 0.11 & 20 \\
\hline
\end{tabular}

Table 4 Utility scores, mean importance and relative importance for each variable in Task 2

\begin{tabular}{llccc}
\hline Variable & Option & $\begin{array}{c}\text { Mean } \\
\text { Utility } \\
\text { score }\end{array}$ & SEM & $\begin{array}{c}\text { Mean } \\
\text { importance } \\
\text { (\%) }\end{array}$ \\
\hline Drug label status & On label & 0.3305 & 0.04 & 10 \\
& Off label & -0.3305 & & \\
Frequency of visits & Monthly & 0.5000 & 0.16 & 18 \\
& 2 Monthly & 1.0000 & & 61 \\
Vision & Good & -2.2236 & 0.07 & \\
& Moderate & -4.4472 & & 10 \\
Poor & -6.6708 & & \\
& Low cost & -0.4080 & 0.10 & \\
\hline
\end{tabular}


Table 5 Table summarising the results of the stepwise linear regression models with probability of inclusion is 0.05 and 0.10 for exclusion

\begin{tabular}{llcc}
\hline Dependant & Independent & $\begin{array}{c}\text { B regression } \\
\text { coefficient }\end{array}$ & SE of B \\
\hline $\begin{array}{l}\text { Design one } \\
\text { Clinic setup (one-stop) }\end{array}$ & Travel time & 0.0073 & 0.0033 \\
Length of wait & Visual acuity in better eye (logMAR) & 0.49 \\
Frequency of visit & Gender (female) & -0.1 .1 & 0.43 \\
Status of Injector & None entered & 0.91 & 0.03 \\
Design two & None entered & & 0.04 \\
Vision & None entered & & 0.016 \\
Frequency of visit & Age & & 0.039 \\
Cost to NHS (low cost) & Hospital transport & 0.97 & 0.02 \\
Status of drug (licensed) & Travel time & -0.0048 & 0.02 \\
\hline
\end{tabular}

For categorical dichotomous variables the value of the higher value is in parentheses.

\section{Discussion}

The relative importance of each of the options reflects how prepared patients are to trade-off one aspect of their care that they prefer for another. The most important factor to the patients was maintenance of good vision, which is not unexpected. The next most desirable factor was to have a 1 stop service so patients can avoid having to make a return journey to receive their injection.

This was followed by the frequency of attendances, with patients preferring to come less frequently (8 weekly). Many of these patients are elderly and have significant co-morbidities and find the frequent visits quite a burden. This is consistent with the findings of a questionnaire survey performed on patients in Cologne, Germany where patients again expressed preference for bi-monthly rather than monthly visits. ${ }^{17}$ Patients also expressed a preference for shorter waiting times, as a survey of Spanish patients also found, ${ }^{18}$ but this was less important than attending once every 8 weeks.

Preference for doctor injectors was low and this broadly supports the use of training nurses to perform intravitreal injections. Nurse injectors have been demonstrated to be able to provide a safe and effective injection service that is well received by patients., 9

Costs to the NHS and drug label status were of the least importance to patients and this has potential important consequences to the way off-label drugs are used. There is much in the recent literature debating the use of off-label anti-VEGF agents due to their significant cost saving. ${ }^{20,21}$ Large randomised controlled trials comparing Avastin and Lucentis have concluded that these drugs are equally efficacious but the studies were not powered to detect differences in safety. ${ }^{22,23}$

The multivariate linear regression model for the factor of cost to the NHS showed that patient age and whether they used hospital transport were predictors of importance being attached to low cost to the NHS.
Those on hospital transport are likely to be more aware of cost issues and the elderly also seem to be instinctively more cost conscious.

The use of off-label or unlicensed drugs in ophthalmology is commonplace, for example, gases in vitreo-retinal surgery, intravitreal trimacinolone in diabetic, or vein occlusion related macular oedema, 5-FU and MMC used routinely in glaucoma surgery are all unlicensed and until recently intracameral cefuroxime used for endophthalmitis prophylaxis in cataract surgery was unlicensed.

The only predictor in the model for preference as to whether the license was on- or off-label was travel time with those living near the hospital having a preference for the drug to be on-label. Nottingham serves both a city and a rural community with the latter having to travel further and thus travel time may be a proxy measure of social class or community. We are unable to explore this association further.

The use of off-label anti-VEGF drugs varies across the country and internationally, with the use of Avastin exceeding that of Lucentis in North America. ${ }^{24}$ The overall NHS expenditure on medicines in 2013-2014 was $£ 14.4$ billion. In 2013-2014, hospital use accounted for $40.1 \%$ of the total cost, up from $37.5 \%$ in $2012-2013 .{ }^{25}$ The second most expensive drug, whose total cost was $£ 244 \mathrm{~m}$, was ranibizumab (Lucentis). ${ }^{26}$

This study shows that many patients would accept the use of an off-label medication as long it was as effective as the alternative(s). The regression analysis demonstrated that the patients most concerned with cost to the NHS were those of older age and those who use hospital transport. These patients are likely to be the heaviest users of the multiple NHS services and as such may have a more holistic view of the organisation. This may endow them with a direct appreciation that increased spending in one service may adversely affect another of which they also avail. 
This study can be compared with a post-marketing study; in this case a post-treatment study. Values and attitudes can depend on a number of factors and can change over time and between places. This is an inherent limitation to all such studies and it is unclear how far it is possible to extrapolate these results to other populations.

Patient-centred care is ever more important and was a key theme in the report by Robert Francis QC, making sure that patients' voices are heard and used to deliver better services, ${ }^{10}$ and the major strength of this study is that it is one of the few attempts in the medical literature to attempt to elicit nAMD patients' views on how they would like the service that treats them to be organised (we have been unable to find any similar studies in the published medical literature). This paper encompasses the views of 95 patients and so it represents a reasonably sized body of opinion and can help inform planning decisions; which are too often made on the basis of speculation.

The methodology of conjoint analysis was developed by those interested in market research and represents one of the most robust ways of determining opinion but it is limited in the number of factors that anyone conjoint study can take into account (the limitation being a pragmatic rather than a theoretical limit as there is a limit to the number of scenarios that subjects can meaningfully rank). A particular strength of this methodology is that expression of a preference in the form of a choice is one that can be performed even by those with mild to moderate cognitive impairment. There is no requirement to explain or justify their reasons and it allows their voice to also be heard.

In conclusion, patients demonstrate a clear preference for good vision and this dominated over all other factors. The next set of factors all related to minimising the number of visits and the amount of time each visit took. Most patients did not have strong views on whether there medication was on or off label or whether there treatment was delivered by a doctor or a nurse lead service.

\section{Summary}

What was known before

- There are a number of competing medications known to be effective in the treatment of nAMD but with different costs and license status. Different institutions have different methods logistically of managing their nAMD outpatient services.

\section{What this study adds}

- Patients concerns are dominated by the effectiveness of the treatment (a strong preference for good vision). Patients next strongest preferences are for reduced number of visits. Patients have little concern with respect to licensing/label status. Patients find nurse injectors acceptable. These findings have clear policy implications.

\section{Conflict of interest}

The authors declare no conflict of interest.

\section{References}

1 Owen CG, Fletcher AE, Donoghue M, Rudnicka AR. How big is the burden of visual loss caused by age related macular degeneration in the United Kingdom? Br J Ophthalmol 2003; 87: 312-317.

2 Owen CG, Jarrar Z, Wormald R, Cook DG, Fletcher AE, Rudnicka AR. The estimated prevalence and incidence of late stage age related macular degeneration in the UK. Br J Ophthalmol 2012; 96: 752-756.

3 Brown DM, Kaiser PK, Michels M, Soubrane G, Heier JS, Kim RY et al. Ranibizumab versus verteporfin for neovascular age-related macular degeneration. N Engl J Med 2006; 355: 1432-1444.

4 Rosenfeld PJ, Brown DM, Heier JS, Boyer DS, Kaiser PK, Chung CY et al. Ranibizumab for neovascular age-related macular degeneration. $N$ Engl J Med 2006; 355: 1419-1431.

5 Martin DF, Maguire MG, Fine SL, Ying GS, Jaffe GJ, Grunwald JE et al. Ranibizumab and bevacizumab for treatment of neovascular age-related macular degeneration: 2-year results. Ophthalmology 2012; 119: 1388-1398.

6 Kodjikian L, Souied EH, Mimoun G, Mauget-Faÿsse M, Behar-Cohen F, Decullier E et al. Ranibizumab versus bevacizumab for neovascular age-related macular degeneration: results from the GEFAL noninferiority randomized trial. Ophthalmology 2013; 120: 2300-2309.

7 Chakravarthy U, Harding SP, Rogers CA, Downes SM, Lotery AJ, Culliford LA et al. Alternative treatments to inhibit VEGF in age-related choroidal neovascularisation: 2-year findings of the IVAN randomised controlled trial. Lancet 2013; 382: 1258-1267.

8 Heier JS, Brown DM, Chong V, Korobelnik JF, Kaiser PK, Nguyen QD et al. Intravitreal aflibercept (VEGF trap-eye) in wet age-related macular degeneration. Ophthalmology 2012; 119: 2537-2548.

9 Simcock P, Kingett B, Mann N, Reddy V, Park J. A safety audit of the first 10000 intravitreal ranibizumab injections performed by nurse practitioners. Eye 2014; 28: 1161-1164.

10 NHS England» Putting Patients First: The NHS England Business Plan for 2013/2014-2015/2016. Available at http:/ / www.england.nhs.uk/pp-1314-1516/ (accessed on 7 December 2014).

11 Parker BR, Srinivasan V. A consumer preference approach to the planning of rural primary health-care facilities. Oper Res 1976; 24: 991-1025.

12 Ryan M, Farrar S. Using conjoint analysis to elicit preferences for health care. BMJ 2000; 320: 1530-1533.

13 Bhargava JS, Patel B, Foss AJE, Avery AJ, King AJ. Views of glaucoma patients on aspects of their treatment: an assessment of patient preference by conjoint analysis. Invest Ophthalmol Vis Sci 2006; 47: 2885-2888.

14 Bhargava JS, Bhan-Bhargava A, Foss AJE, King AJ. Views of glaucoma patients on provision of follow-up care; an assessment of patient preferences by conjoint analysis. Br J Ophthalmol 2008; 92: 1601-1605.

15 Ross M-A, Avery AJ, Foss AJE. Views of older people on cataract surgery options: an assessment of preferences by conjoint analysis. Qual Saf Health Care 2003; 12: 13-17. 
16 Danner M, Vennedey V, Hiligsmann M, Fauser S, Stock S. Focus groups in elderly ophthalmologic patients: setting the stage for quantitative preference elicitation. Patient 2016; 9(1): 47-57.

17 Droege K, Caramoy A, Kersten A, Luberichs-Fauser J, Zilkens K, Müller D et al. Patient preference of ranibizumab treatment regimen for neovascular age-related macular degeneration- monthly injections versus pro re nata. Graefes Arch Clin Exp Ophthalmol 2014; 252: 31-34.

18 Rodríguez Ramírez M, del Barrio Manso MI, Martín Sánchez MD. Intravitreal injections: What do patients prefer? Analysis of patient's satisfaction and preferences about where to perform intravitreal injections. Arch Soc Esp Oftalmol 2014; 89(12): 477-483.

19 Kelly SP, Michelotti M, Abugreen S, Morarji J, Myerscough D, Boddie T et al. Transformational change: nurses substituting for ophthalmologists for intravitreal injections - a quality-improvement report. Clin Ophthalmol 2014; 8: 755-761.

20 NHS 'should use cancer drug for eyes'. BBC 2014.

Available at http://www.bbc.co.uk/news/health-30138097 (accessed on 7 December 2014).
21 Lotery A, MacEwen C. What is stopping the NHS from using bevacizumab for macular degeneration and other retinal disorders? BMJ 2014; 349: g6887-g6887.

22 IVAN Study Investigators, Chakravarthy U, Harding SP, Rogers CA, Downes SM, Lotery AJ, Wordsworth S et al. Ranibizumab versus bevacizumab to treat neovascular agerelated macular degeneration: one-year findings from the IVAN randomized trial. Ophthalmology 2012; 119: 1399-1411.

23 CATT research group. Ranibizumab and bevacizumab for neovascular age-related macular degeneration. $N$ Engl J Med 2011; 364: 1897-1908.

24 Curtis LH, Hammill BG, Schulman KA, Cousins SW. Risks of mortality, myocardial infarction, bleeding, and stroke associated with therapies for age-related macular degeneration. Arch Ophthalmol 2010; 128: 1273-1279.

25 Health and Social Care Information Centre UK. Hospital Prescribing: England, 2013-2014. Available at http:/ /www.hscic.gov.uk/pubs/maternity1011. (accessed on 27 December 2014).

26 Hawkes N. Cost of hospital prescribing rose $15 \%$ in a year owing to new rheumatoid arthritis and cancer drugs. BMJ 2014; 349: g6867. 